\title{
Whole-Brain Map of Long-Range Monosynaptic Inputs to Differ- ent Cell Types in the Amygdala of the Mouse
}

\author{
Jia-Yu Fu ${ }^{1} \cdot$ Xiao-Dan $\mathrm{Yu}^{1} \cdot$ Yi Zhu ${ }^{1} \cdot$ Shi-Ze Xie $^{1} \cdot$ Meng-Yu Tang ${ }^{1} \cdot$ \\ Bin $\mathrm{Yu}^{1} \cdot$ Xiao-Ming $\mathrm{Li}^{1,2}$
}

Received: 23 December 2019/Accepted: 13 May 2020/Published online: 20 July 2020

(C) The Author(s) 2020

\begin{abstract}
The amygdala, which is involved in various behaviors and emotions, is reported to connect with the whole brain. However, the long-range inputs of distinct cell types have not yet been defined. Here, we used a retrograde trans-synaptic rabies virus to generate a whole-brain map of inputs to the main cell types in the mouse amygdala. We identified 37 individual regions that projected to neurons expressing vesicular glutamate transporter 2, 78 regions to parvalbumin-expressing neurons, 104 regions to neurons expressing protein kinase $\mathrm{C}-\delta$, and 89 regions to somatostatin-expressing neurons. The amygdala received massive projections from the isocortex and striatum. Several nuclei, such as the caudate-putamen and the CA1 field of the hippocampus, exhibited input preferences to different cell types in the amygdala. Notably, we identified several novel input areas, including the substantia innominata and zona incerta. These findings provide anatomical evidence to help
\end{abstract}

Electronic supplementary material The online version of this article (https://doi.org/10.1007/s12264-020-00545-z) contains supplementary material, which is available to authorized users.

Jia-Yu Fu, Xiao-Dan Yu and Yi Zhu contributed equally to this work.

Xiao-Ming Li

lixm@zju.edu.cn

1 Center for Neuroscience and Department of Neurology of Second Affiliated Hospital, Zhejiang University School of Medicine, Hangzhou 310058, China

2 NHC and CAMS Key Laboratory of Medical Neurobiology, Center for Brain Science and Brain-Inspired Intelligence, Guangdong-Hong Kong-Macao Greater Bay Area, Joint Institute for Genetics and Genome Medicine between Zhejiang University and University of Toronto, Hangzhou 310058, China understand the precise connections and diverse functions of the amygdala.

Keywords Basolateral amygdala $\cdot$ Central amygdala Rabies virus retrograde tracing - Glutamatergic .

GABAergic · Mouse

\section{Introduction}

As a hub responsible for the control of diverse behaviors and the modulation of different emotions such as fear, anxiety, and reward, the amygdala is reported to connect to a large number of brain regions [1-7]. The amygdala consists of the basolateral amygdala (BLA) and the central nucleus of the amygdala (CeA). The BLA receives projections from the medial geniculate nucleus, auditory cortex $(\mathrm{Au})$, and medial prefrontal cortex $(\mathrm{mPFC})$, and projects to various nuclei such as the nucleus accumbens, ventral hippocampus, prelimbic cortex, and CeA [8-13]. Previous studies have reported the long-range connectivity of the CeA, including inputs from the BLA, paraventricular thalamic nucleus (PVT), mPFC, bed nucleus of the stria terminalis (BST), and raphe nucleus, and output projections to the periaqueductal grey, nucleus tractus solitarius, locus coeruleus, and hypothalamus [14-16]. Although various studies have explored the innervation of the amygdala and its outputs, research on whole-brain inputs to specific cell types in the BLA and CeA is lacking.

The BLA is composed of a majority $(80 \%-85 \%)$ of spiny glutamatergic neurons and a minority $(20 \%)$ of GABAergic neurons, including parvalbumin-expressing $\left(\mathrm{PV}^{+}\right)$interneurons [17-21]. These $\mathrm{PV}^{+}$neurons constitute $19 \%-43 \%$ of GABAergic neurons in the BLA, and $>90 \%$ of $\mathrm{PV}^{+}$neurons are GABAergic [22]. The $\mathrm{CeA}$ is a 
striatum-like structure consisting primarily of GABAergic neurons, which can be specifically distinguished by their molecular markers - those expressing protein kinase $\mathrm{C}-\delta$ $\left(\mathrm{PKC}-\delta^{+}, \sim 50 \%\right.$ of GABAergic neurons) and those expressing somatostatin $\left(\mathrm{SST}^{+}, \sim 50 \%\right.$ of $\mathrm{GABAergic}$ neurons - and these markers are rarely co-expressed [23-25]. For these reasons, we chose vesicular-glutamate transporter 2-positive $\left(\mathrm{VGLUT}^{+}\right)$and $\mathrm{PV}^{+}$neurons in the BLA and $\mathrm{PKC}-\delta^{+}$and $\mathrm{SST}^{+}$neurons in the CeA as the main neuronal types in this study.

To provide anatomical evidence to help understand the precise connections and diverse functions of the amygdala, we developed a detailed map of the whole-brain long-range inputs to the amygdala and analyzed the distributions of inputs to the four main cell types in the amygdala.

\section{Methods}

\section{Animals}

All animal experiments were performed according to the guidelines of Zhejiang University for the care and use of laboratory animals. All protocols were approved by the Zhejiang University Animal Experimentation Committee. VGLUT2-IRES-Cre (no. 016963) [26], PV-IRES-Cre (no. 008069) [27], SST-IRES-Cre (no. 013044) [28], and Ail4 mice (no. 007914) [29] were from the Jackson Laboratory (Bar Harbor, USA). The PKC- $\delta$-IRES-Cre mice [30] were kindly provided by Prof. Hao-Hong Li (Huazhong University of Science and Technology, China). Adult male mice (4 per group) aged 2-4 months were used in the experiments. All mice were housed with food and water provided ad libitum under a 12-h dark-light cycle at $22 \pm 1{ }^{\circ} \mathrm{C}$ and $55 \% \pm 5 \%$ humidity.

\section{Viruses and Viral Injections}

All viruses used in the trans-synaptic retrograde tracing experiments [rAAV-EF1 $\alpha$-DIO-RVG $\left(5.53 \times 10^{12}\right.$ genomic copies $(\mathrm{mL})$, rAAV-CAG-DIO-TVA-EGFP $\left(5.22 \times 10^{12}\right.$ genomic copies $\left./ \mathrm{mL}\right)$, and RV-ENVA- $\Delta \mathrm{G}$ dsRed $\left(3.0 \times 10^{8}\right.$ genomic copies $\left./ \mathrm{mL}\right)$ ] were provided by BrainVTA (Wuhan, China). For rabies virus tracing, rAAV-EF1 $\alpha$-DIO-RVG and rAAV-CAG-DIO-TVA-EGFP were mixed at a ratio of $1: 1$. A $100-\mathrm{nL}$ mixture was unilaterally injected into the BLA or CeA of mice. Three weeks later, $200 \mathrm{~nL}$ of RV-ENVA- $\Delta \mathrm{G}$-dsRed was injected in the same place. Mice were perfused one week later, and their brains were sectioned for fluorescence imaging.

\section{Animal Surgery}

Mice were anesthetized with sodium pentobarbital $(50 \mathrm{mg} /$ $\mathrm{kg}$, intraperitoneal injection). Surgery was performed with each mouse fixed in a stereotaxic frame (RWD Life Science, Shenzhen, China). The viral injection coordinates (in $\mathrm{mm}$, from midline, bregma, and dorsal surface) were: BLA (2.95, - 0.96, - 4.95) and CeA $(2.85,-0.95,-4.50)$.

\section{Histology and Imaging}

Each mouse was anesthetized with sodium pentobarbital $(100 \mathrm{mg} / \mathrm{kg}$, intraperitoneal injection) and transcardially perfused with phosphate-buffered saline (PBS), followed by $4 \%$ paraformaldehyde in PBS. The brain was removed and post-fixed in $4 \%$ paraformaldehyde for $4-6 \mathrm{~h}$ at $4{ }^{\circ} \mathrm{C}$, immersed in 30\% sucrose $(w / v)$ in PBS for $48 \mathrm{~h}$, and then embedded in Optimal Cutting Temperature compound. Coronal cryosections were cut at $50 \mu \mathrm{m}$ (Leica CM1950) and washed three times with PBS (5 min each).

For immunofluorescence staining, sections were blocked with 3\% bovine serum albumin in PBST $(0.3 \%$ Triton $\mathrm{X}-100$ in PBS) for $1 \mathrm{~h}$ and incubated with primary antibodies overnight at $4{ }^{\circ} \mathrm{C}$. After incubation, the sections were washed and incubated with a fluorescent dye-conjugated secondary antibody (1:400, Invitrogen, Carlsbad, USA) for $2 \mathrm{~h}$ at room temperature. The primary antibodies were anti-PV (1:1000, PV 27, Swant, Marly, Switzerland), anti-PKC- $\delta$ (1:500, \#610398, BD Biosciences, San Jose, USA), and anti-SST (1:500, \#20067, Immunostar, Hudson, USA). After staining with the nuclear dye 4,6-diamidino-2phenylindole (Sigma-Aldrich, St. Louis, USA), the sections were used for imaging.

Confocal images were captured under a $20 \times$ objective (numerical aperture 1.2) using an A-1R confocal microscope (Nikon, Tokyo, Japan) and large images were captured under a $10 \times$ objective using a Virtual Slide microscope VS120 (Olympus, Tokyo, Japan).

\section{Cell Counts and Statistics}

We sampled every fourth $50-\mu \mathrm{m}$ section from bregma $+2.5 \mathrm{~mm}$ to $-5 \mathrm{~mm}$. Each section was matched to the corresponding atlas level of the Allen Adult Mouse Brain Atlas and Allen Mouse Common Coordinate Framework and Reference Atlas [31, 32]. We then counted the number of dsRed-expressing neurons in individual nuclei within the entire brain of each mouse from rostral to caudal using ImageJ v1.52n software (NIH, Bethesda, USA) manually and blindly. Regions within $\sim 600 \mu \mathrm{m}$ of the injection site were omitted from the data (BLA, CeA, medial and basomedial amygdalar nuclei). All values are presented as the mean \pm SEM. Two-way analysis of variance 
(ANOVA) was used for group differences and Sidak's test was used for multiple comparisons with GraphPad Prism 6 v6.01 (GraphPad Software, San Diego, USA). Differences were considered statistically significant when $P<0.05$.

\section{Results}

\section{Experimental Strategy}

To build a cell-type-specific whole-brain map of inputs to the BLA and CeA, we used four mouse strains: VesicularGlutamate-Transporter-2-IRES-Cre mice (VGLUT2-IRESCre) for VGLUT2 $^{+}$glutamatergic neurons in the BLA, Parvalbumin-IRES-Cre mice (PV-IRES-Cre) for $\mathrm{PV}^{+}$neurons in the BLA, and Protein-Kinase- $C-\delta$-IRES-Cre mice (PKC- $\delta$ IRES-Cre) and Somatostatin-IRES-Cre mice (SST-IRES-Cre) for the two major GABAergic subtypes in the CeA. First, specific Cre-positive neurons were infected with two Credependent rAAVs that expressed TVA receptor-EGFP and rabies glycoprotein (RVG). Second, ENVA-pseudotyped RVG-deleted rabies virus (dsRed) specifically infected TVA-expressing cells, and only spread when RVG was provided [33]. The experimental strategies are shown in Fig. 1A. Neurons expressing both dsRed and EGFP were labeled as starter cells. Representative images for the starter cells of each Cre line mouse are shown in Figs 2A, 3A, 4A, and $5 \mathrm{~A}$. One week after the rabies virus injection, the mice were sacrificed and whole-brain sections were cut for imaging. For each cell type, we injected 5-6 mice with the rabies virus. Only those mice in which starter cells were specifically expressed in the target region were counted (Fig. S1).

In control experiments, we injected the same two helper viruses into the BLA or CeA of wild-type mice ( $n=3$ /group), followed by the same rabies viruses injected into the same place three weeks later to test the leakage of the rabies virus-tracing system. There was no labeling of either EGFP or dsRed in the BLA or CeA (Fig. S2). These data indicated that the rabies virus did not infect Crenegative neurons in our experiments. To confirm the selectivity of Cre recombinase, we crossed Cre mice with Ai14 mice, followed by staining with cell-type-specific markers (Fig. S3). We found that only a few markernegative neurons $(4.7 \%-7.0 \%)$ expressed Cre recombinase in all three strains.

We calculated the ratio between the number of input cells and starter cells. The results showed that different cell subtypes in the BLA and CeA received a comparable number of input cells per starter cell (Fig. 1B-E). The numbers of starter and input cells are shown in Supplementary Table S3. We provide input nuclei with input percentages $>1 \%$ (defined as percentage of input cells in each nucleus to total input cells throughout the whole brain) for $\mathrm{BLA}_{\mathrm{VGLUT2}}{ }^{+}$mice, $\mathrm{BLA} \mathrm{PV}^{+}$mice, $\mathrm{CeA}$ PKC- $\delta^{+}$mice, and CeA SST ${ }^{+}$mice in Figs $2,3,4,5$. Many upstream nuclei with input percentages $<1 \%$ were traced and are listed in Supplementary Table S1.

\section{Identification of Major Long-range Inputs to BLA VGLUT2 $^{+}$Glutamatergic Neurons}

Whole-brain mapping of RV-dsRed-labeled neurons revealed inputs from 37 discrete regions to BLA glutamatergic neurons. Those input nuclei with percentages $>1 \%$ are listed in Fig. 2C. Dense long-range inputs with dsRed-labeled cells were observed in the caudate-putamen $(\mathrm{CPu})$, the $\mathrm{CA} 1$ field of the hippocampus (CA1), piriform cortex (Pir), Au, agranular insular cortex (AI), lateral entorhinal cortex, PVT, and substantia innominata (SI) (Fig. 2B). We dissected all the input nuclei into eight areas. The majority of input nuclei were located in the striatum $(30.67 \% \pm 3.38 \%)$, followed by the isocortex $(22.52 \% \pm$ $3.16 \%)$, hippocampal formation $(13.57 \% \pm 2.88 \%)$, olfactory areas $(13.03 \% \pm 1.87 \%)$, thalamus $(9.49 \% \pm 1.54 \%)$, pallidum $(6.05 \% \pm 2.16 \%)$, midbrain $(3.35 \% \pm 0.95 \%)$, and hypothalamus $(1.24 \% \pm 0.74 \%)$ (Fig. 6C).
Fig. 1 Virus injection strategy. A Schematic of viral vectors and rabies virus-mediated trans-synaptic retrograde tracing of amygdala inputs. B-E Ratios of input cells to starter cells in BLA VGLUT2-Cre mice (B), BLA PV-Cre mice $(\mathbf{C}), \mathrm{CeA}$ PKC- $\delta$-Cre mice $(\mathbf{D})$, and $\mathrm{CeA}$ SST-Cre mice (E) $(n=4$ /group, mean \pm SEM).
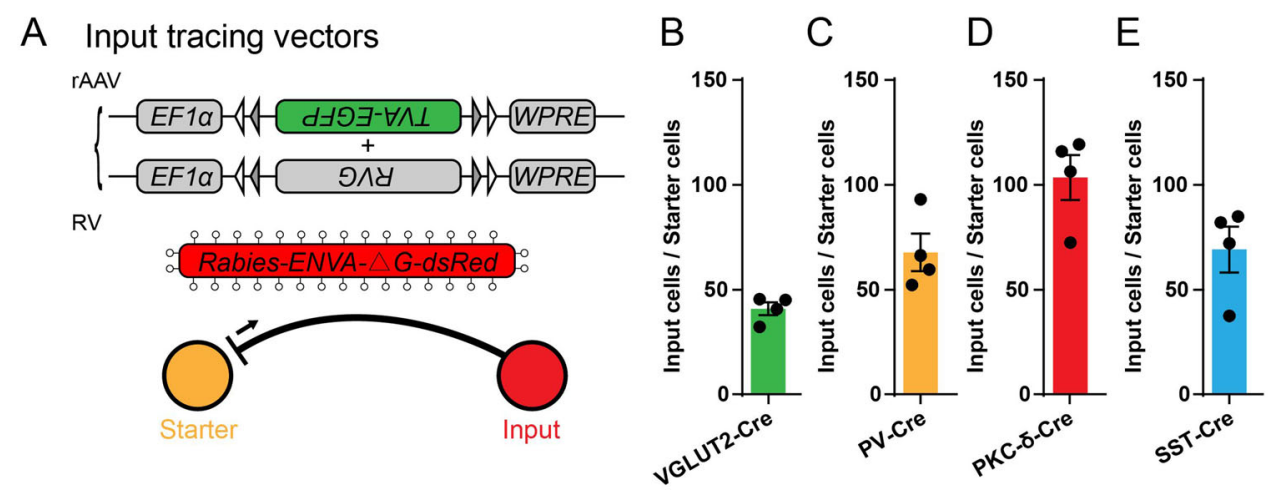


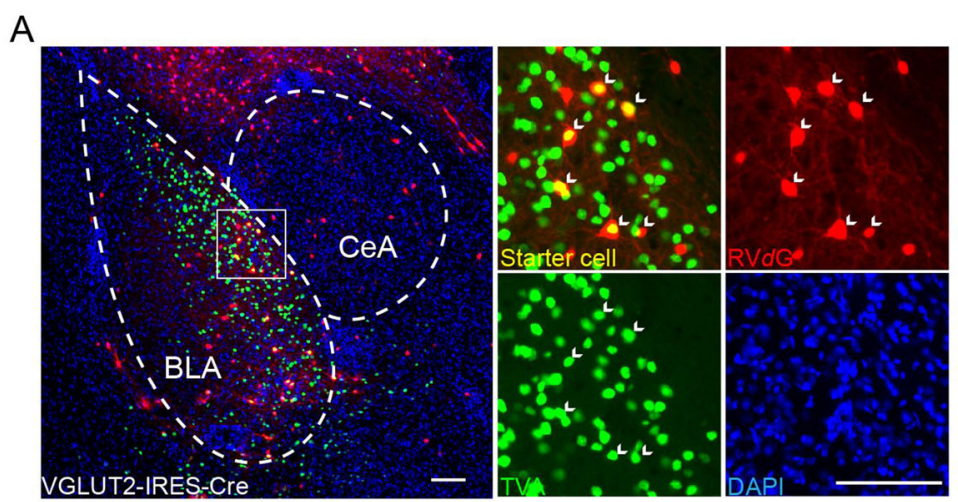

B Distance from bregma $(\mathrm{mm})$
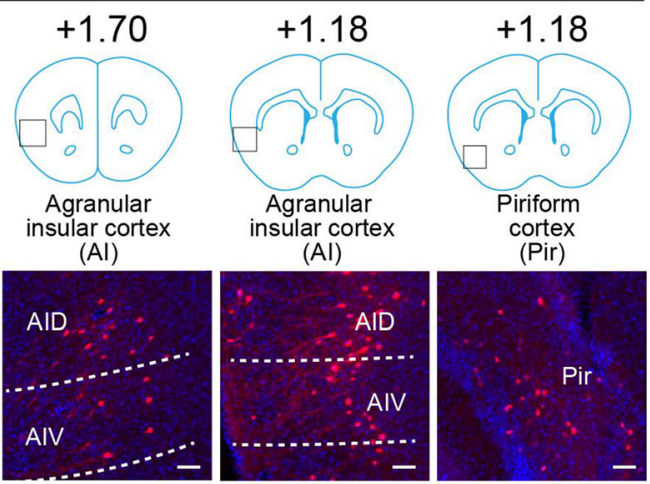

C
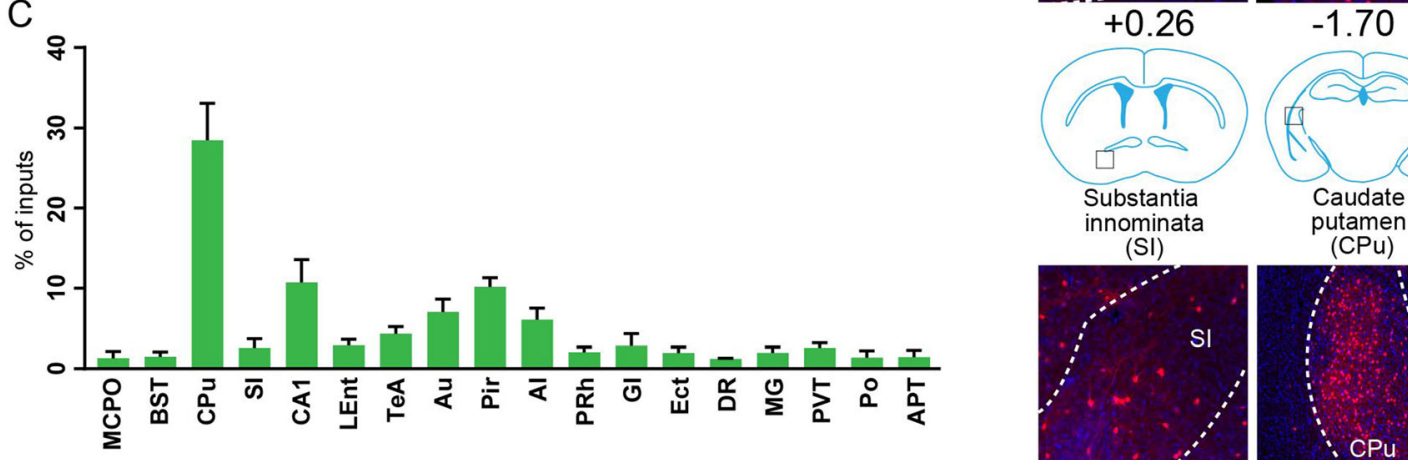

$-2.18$
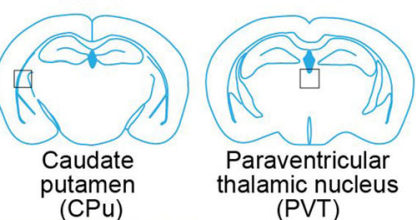

(SI)
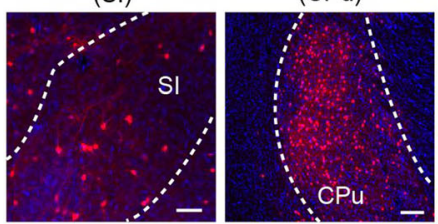
(PVT)

D

Fraction of dsRed ${ }^{+}$ input neurons
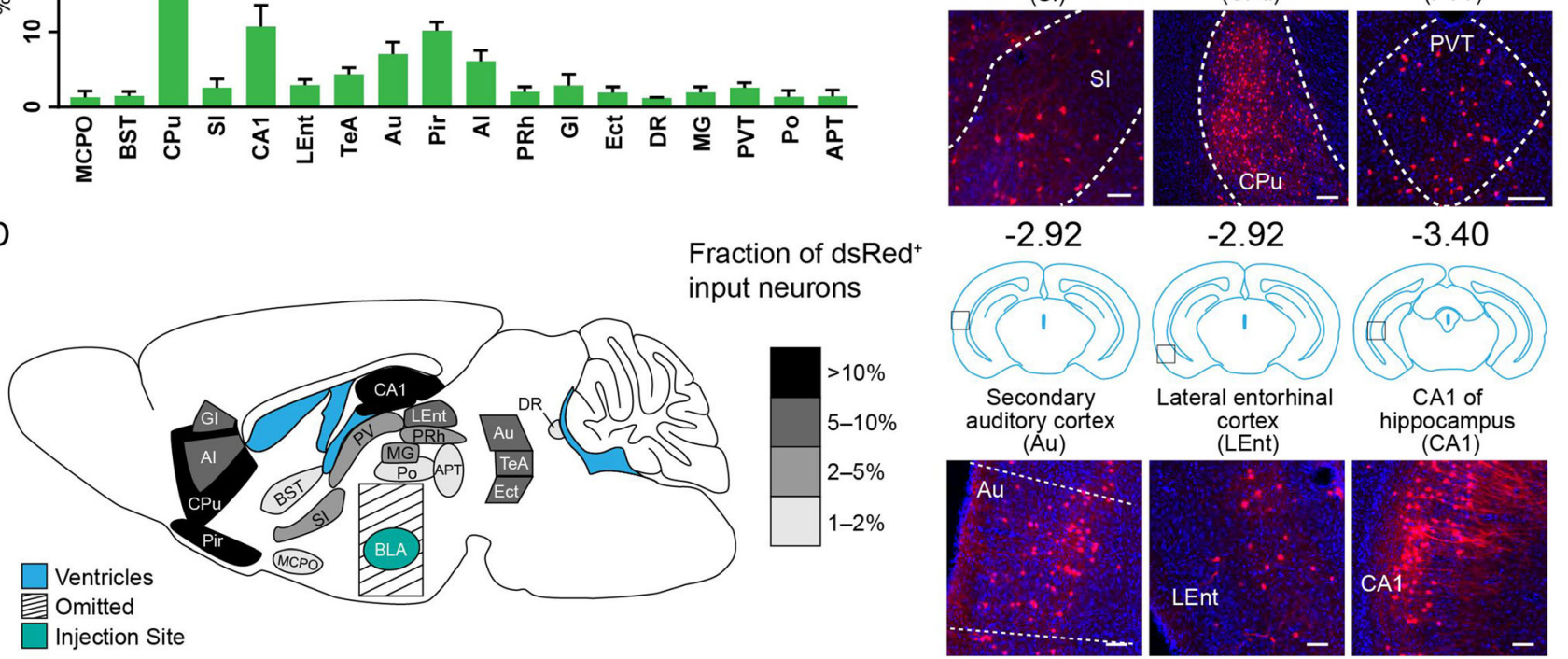

Fig. 2 Long-range inputs to BLA VGLUT2 ${ }^{+}$neurons. A Representative images of starter cells restricted to the BLA. Starter cells expressed both GFP and dsRed fluorescent proteins were marked by arrowheads. Scale bars, $100 \mu \mathrm{m}$. B Representative images of RVlabeled input neurons to BLA $\mathrm{VGLUT}^{+}$neurons from selected

\section{Identification of Major Long-range Inputs to BLA $\mathbf{P V}^{+}$GABAergic Interneurons}

Whole-brain mapping of RV-dsRed-labeled neurons revealed inputs from 78 discrete regions to $\mathrm{BLA} \mathrm{PV}^{+}$ neurons. Those input nuclei with percentages $>1 \%$ are listed in Fig. 3C. Dense long-range inputs with dsRedlabeled cells were observed in the Pir, lateral entorhinal cortex, perirhinal cortex, AI, medial orbital cortex, PVT, $\mathrm{CPu}$, SI, and CA1 (Fig. 3B). We dissected all input nuclei into eight areas. The majority of input nuclei were located in olfactory areas $(24.98 \% \pm 1.88 \%)$, followed by the

nuclei. Scale bars, $100 \mu \mathrm{m}$. C Whole-brain distribution of input nuclei to BLA VGLUT2 ${ }^{+}$neurons with input percentages $>1 \%$ (mean \pm SEM). D Schematic summary of brain regions providing the largest average fractional inputs to BLA VGLUT2 ${ }^{+}$neurons. Abbreviations are shown in Table 1.

isocortex $(23.85 \% \pm 3.73 \%)$, hippocampal formation $(13.51 \% \pm 5.42 \%)$, pallidum $(9.01 \% \pm 2.52 \%)$, thalamus $(7.80 \% \pm 1.09 \%)$, striatum $(7.04 \% \pm 3.04 \%)$, midbrain $(2.82 \% \pm 0.91 \%)$, and hypothalamus $(1.88 \% \pm 0.34 \%)$ (Fig. 6C).

\section{Identification of Major Long-range Inputs to CeA PKC- $\delta^{+}$GABAergic Neurons}

Whole-brain mapping of RV-dsRed-labeled neurons revealed inputs from 104 discrete regions to CeA PKC$\delta^{+}$neurons. Those input nuclei with percentages $>1 \%$ are 
Table 1 Abbreviations and classifications of brain structures.

\begin{tabular}{|c|c|c|}
\hline Abbreviation & Name & Parent Brain Region \\
\hline AAA & Anterior amygdalar area & Striatum \\
\hline Acb & Accumbens nucleus, shell & Striatum \\
\hline ACo & Anterior cortical amygdaloid nucleus & Olfactory areas \\
\hline $\mathrm{AD}$ & Anterodorsal thalamic nucleus & Thalamus \\
\hline ADP & Anterodorsal preoptic nucleus & Hypothalamus \\
\hline $\mathrm{AH}$ & Anterior hypothalamic area & Hypothalamus \\
\hline AHi & Amygdalohippocampal area & Hippocampal formation \\
\hline AI & Agranular insular cortex & Isocortex \\
\hline $\mathrm{AM}$ & Anteromedial thalamic nucleus & Thalamus \\
\hline AOP & Anterior olfactory nucleus, posterior part & Olfactory areas \\
\hline Apir & Amygdalopiriform transition area & Olfactory areas \\
\hline APT & Anterior pretectal nucleus & Midbrain \\
\hline Arc & Arcuate hypothalamic nucleus & Hypothalamus \\
\hline $\mathrm{Au}$ & Auditory cortex & Isocortex \\
\hline AV & Anteroventral thalamic nucleus & Thalamus \\
\hline $\mathrm{BIC}$ & Nucleus of the brachium of the inferior colliculus & Fiber tracts \\
\hline BST & Bed nucleus of the stria terminalis & Pallidum \\
\hline CA1 & Field CA1 of the hippocampus & Hippocampal formation \\
\hline $\mathrm{Cg}$ & Cingulate cortex & Isocortex \\
\hline $\mathrm{CM}$ & Central medial thalamic nucleus & Thalamus \\
\hline $\mathrm{Cpu}$ & Caudate putamen (striatum) & Striatum \\
\hline $\mathrm{CxA}$ & Cortex-amygdala transition zone & Olfactory areas \\
\hline DG & Dentate gyrus & Hippocampal formation \\
\hline DI & Dysgranular insular cortex & Isocortex \\
\hline DLG & Dorsal lateral geniculate nucleus & Thalamus \\
\hline DLO & Dorsolateral orbital cortex & Isocortex \\
\hline DM & Dorsomedial hypothalamic nucleus & Hypothalamus \\
\hline DP & Dorsal peduncular cortex & Olfactory areas \\
\hline DpG & Deep gray layer of the superior colliculus & Midbrain \\
\hline $\mathrm{DpMe}$ & Deep mesencephalic nucleus & Midbrain \\
\hline DR & Dorsal raphe nucleus & Midbrain \\
\hline DT & Dorsal terminal nucleus of the accessory optic tract & Midbrain \\
\hline DTT & Dorsal tenia tecta & Fiber tracts \\
\hline ECIC & External cortex of the inferior colliculus & Midbrain \\
\hline Ect & Ectorhinal cortex & Isocortex \\
\hline Ent & Entorhinal cortex & Hippocampal formation \\
\hline EP & Endopiriform nucleus & Cortical subplate \\
\hline Eth & Ethmoid thalamic nucleus & Thalamus \\
\hline GI & Glomerular layer of the olfactory bulb & Olfactory areas \\
\hline Gus & Gustatory thalamic nucleus & Thalamus \\
\hline HDB & Nucleus of the horizontal limb of the diagonal band & Pallidum \\
\hline HIP & Hippocampal region & Hippocampal formation \\
\hline I & Intercalated nuclei of the amygdala & Striatum \\
\hline IAD & Interanterodorsal thalamic nucleus & Thalamus \\
\hline IAM & Interanteromedial thalamic nucleus & Thalamus \\
\hline IF & Interfascicular nucleus & Midbrain \\
\hline IGL & Intergeniculate leaf & Thalamus \\
\hline IL & Infralimbic cortex & Isocortex \\
\hline
\end{tabular}


Table 1 continued

\begin{tabular}{|c|c|c|}
\hline Abbreviation & Name & Parent Brain Region \\
\hline $\mathrm{IM}$ & Intercalated amygdaloid nucleus & Striatum \\
\hline IMD & Intermediodorsal thalamic nucleus & Thalamus \\
\hline InG & Intermediate gray layer of the superior colliculus & Midbrain \\
\hline InWh & Intermediate white layer of the superior colliculus & Midbrain \\
\hline IP & Interpeduncular nucleus & Midbrain \\
\hline IPAC & Interstitial nucleus of the posterior limb of the anterior commissure & Striatum \\
\hline LA & Lateroanterior hypothalamic nucleus & Hypothalamus \\
\hline LEnt & Lateral entorhinal cortex & Hippocampal formation \\
\hline LGP & Lateral globus pallidus & Pallidum \\
\hline LH & Lateral hypothalamic area & Hypothalamus \\
\hline $\mathrm{LHb}$ & Lateral habenular nucleus & Thalamus \\
\hline $\mathrm{LO}$ & Lateral orbital cortex & Isocortex \\
\hline LOT & Nucleus of the lateral olfactory tract & Olfactory areas \\
\hline LP & Lateral posterior thalamic nucleus & Thalamus \\
\hline LPB & Lateral parabrachial nucleus & Pons \\
\hline LPO & Lateral preoptic area & Hypothalamus \\
\hline LS & Lateral septal nucleus & Striatum \\
\hline LSI & Lateral septal nucleus, intermediate part & Striatum \\
\hline M1 & Primary motor cortex & Isocortex \\
\hline MCLH & Magnocellular nucleus of the lateral hypothalamus & Hypothalamus \\
\hline MCPO & Magnocellular preoptic nucleus & Pallidum \\
\hline MD & Mediodorsal thalamic nucleus & Thalamus \\
\hline $\mathrm{Me}$ & Medial amygdaloid nucleus & Striatum \\
\hline MG & Medial geniculate nucleus & Thalamus \\
\hline MGP & Medial globus pallidus & Pallidum \\
\hline MiTg & Microcellular tegmental nucleus & Midbrain \\
\hline $\mathrm{MnPO}$ & Median preoptic nucleus & Hypothalamus \\
\hline $\mathrm{MnR}$ & Median raphe nucleus & Midbrain \\
\hline MO & Medial orbital cortex & Isocortex \\
\hline MPA & Medial preoptic area & Hypothalamus \\
\hline MPO & Medial preoptic nucleus & Hypothalamus \\
\hline MS & Medial septal nucleus & Pallidum \\
\hline Mtu & Medial tuberal nucleus & Hypothalamus \\
\hline NDB & Diagonal band nucleus & Pallidum \\
\hline OLF & Medial geniculate nucleus & Thalamus \\
\hline op & Optic nerve layer of the superior colliculus & Midbrain \\
\hline ORB & Orbital area & Isocortex \\
\hline $\mathrm{Pa}$ & Paraventricular hypothalamic nucleus & Hypothalamus \\
\hline $\mathrm{Pa} 4$ & Paratrochlear nucleus & Midbrain \\
\hline PAG & Periaqueductal gray & Midbrain \\
\hline PAL & Pallidum & Pallidum \\
\hline $\mathrm{PB}$ & Parabrachial nucleus & Pons \\
\hline $\mathrm{Pe}$ & Periventricular hypothalamic nucleus & Hypothalamus \\
\hline PERI & Perirhinal area & Isocortex \\
\hline $\mathrm{PF}$ & Parafascicular thalamic nucleus & Thalamus \\
\hline $\mathrm{PH}$ & Posterior hypothalamic area & Hypothalamus \\
\hline PIL & Posterior intralaminar thalamic nucleus & Thalamus \\
\hline Pir & Piriform cortex & Olfactory areas \\
\hline
\end{tabular}


Table 1 continued

\begin{tabular}{|c|c|c|}
\hline Abbreviation & Name & Parent Brain Region \\
\hline PL & Paralemniscal nucleus & Fiber tracts \\
\hline PLCo & Posterolateral cortical amygdaloid nucleus & Olfactory areas \\
\hline PMCo & Posteromedial cortical amygdaloid nucleus & Olfactory areas \\
\hline $\mathrm{PN}$ & Paranigral nucleus & Midbrain \\
\hline Po & Posterior thalamic nuclear group & Thalamus \\
\hline PP & Peripeduncular nucleus & Thalamus \\
\hline PPT & Posterior pretectal nucleus & Midbrain \\
\hline PPTg & Pedunculopontine tegmental nucleus & Midbrain \\
\hline PR & Prerubral field & Hypothalamus \\
\hline $\mathrm{PRh}$ & Perirhinal cortex & Isocortex \\
\hline PrL & Prelimbic cortex & Isocortex \\
\hline PSTh & Parasubthalamic nucleus & Hypothalamus \\
\hline PT & Paratenial thalamic nucleus & Thalamus \\
\hline $\mathrm{pv}$ & Periventricular fiber system & Hypothalamus \\
\hline PVT & Paraventricular thalamic nucleus & Thalamus \\
\hline Py & Pyramidal cell layer of the hippocampus & Hippocampal formation \\
\hline $\mathrm{RCh}$ & Retrochiasmatic area & Hypothalamus \\
\hline $\operatorname{Re}$ & Reuniens thalamic nucleus & Thalamus \\
\hline $\mathrm{Rh}$ & Rhomboid thalamic nucleus & Thalamus \\
\hline RLi & Rostral linear nucleus of the raphe & Midbrain \\
\hline RR & Retrorubral nucleus & Midbrain \\
\hline RRF & Retrorubral field & Midbrain \\
\hline RSA & Retrosplenial agranular cortex & Isocortex \\
\hline Rt & Reticular thalamic nucleus & Thalamus \\
\hline $\mathrm{S}$ & Subiculum & Hippocampal formation \\
\hline SS & Somatosensory cortex & Isocortex \\
\hline $\mathrm{SC}$ & Superior colliculus & Midbrain \\
\hline $\mathrm{SCh}$ & Suprachiasmatic nucleus & Hypothalamus \\
\hline SFi & Septofimbrial nucleus & Striatum \\
\hline SFO & Subfornical organ & Hypothalamus \\
\hline SG & Suprageniculate thalamic nucleus & Thalamus \\
\hline SI & Substantia innominata & Pallidum \\
\hline $\mathrm{SNC}$ & Substantia nigra, compact part & Midbrain \\
\hline SNL & Substantia nigra, lateral part & Midbrain \\
\hline SNR & Substantia nigra, reticular part & Midbrain \\
\hline SPF & Subparafascicular thalamic nucleus & Thalamus \\
\hline STh & Subthalamic nucleus & Hypothalamus \\
\hline Sub & Submedius thalamic nucleus & Thalamus \\
\hline SubB & Subbrachial nucleus & Thalamus \\
\hline $\mathrm{SuG}$ & Superficial gray layer of the superior colliculus & Midbrain \\
\hline $\mathrm{TC}$ & Tuber cinereum area & Hypothalamus \\
\hline TE & Terete hypothalamic nucleus & Hypothalamus \\
\hline $\mathrm{TeA}$ & Temporal association cortex & Isocortex \\
\hline TS & Triangular septal nucleus & Pallidum \\
\hline $\mathrm{Tu}$ & Olfactory tubercle & Olfactory areas \\
\hline VDB & Nucleus of the vertical limb of the diagonal band & Fiber tracts \\
\hline VIS & Visual cortex & Isocortex \\
\hline VLG & Ventral lateral geniculate nucleus & Thalamus \\
\hline
\end{tabular}


Table 1 continued

\begin{tabular}{llc}
\hline Abbreviation & Name & Parent Brain Region \\
\hline VLPO & Ventrolateral preoptic nucleus & Hypothalamus \\
VMH & Ventromedial hypothalamic nucleus & Hypothalamus \\
VMPO & Ventromedial preoptic nucleus & Hypothalamus \\
VO & Ventral orbital cortex & Isocortex \\
VPM & Ventral posteromedial thalamic nucleus & Thalamus \\
VTA & Ventral tegmental area & Midbrain \\
VTT & Ventral tenia tecta & Olfactory areas \\
ZI & Zona incerta & Hypothalamus \\
\hline
\end{tabular}

listed in Fig. 4C. Dense long-range inputs with dsRedlabeled cells were observed in the CPu, AI, BST, PVT, ventromedial hypothalamic nucleus, posterior thalamic nuclear group, superior colliculus, and nucleus accumbens (Fig. 4B). We dissected all input nuclei into eight areas. The majority of input nuclei were located in the striatum $(30.11 \% \pm 10.96 \%)$, followed by the hypothalamus $(17.07 \% \pm 5.71 \%)$, isocortex $(16.90 \% \pm 1.92 \%)$, midbrain $(9.94 \pm 2.66 \%)$, thalamus $(9.10 \% \pm 3.49 \%)$, pallidum $\quad(7.60 \% \pm 2.80 \%), \quad$ olfactory areas $(3.99 \% \pm 1.32 \%)$, and hippocampal formation $(1.64 \% \pm 0.88 \%)$ (Fig. 6D).

\section{Identification of Major Long-range Inputs to CeA $\mathrm{SST}^{+}$GABAergic Neurons}

Whole-brain mapping of RV-dsRed-labeled neurons revealed inputs from 89 discrete regions to $\mathrm{CeA} \mathrm{SST}^{+}$ neurons. Those input nuclei with percentages $>1 \%$ are listed in Fig. 5C. Dense long-range inputs with dsRedlabeled cells from the anterior to posterior brain were observed in CA1, AI, Au, temporal association cortex, PVT, BST, SI, parasubthalamic nucleus, and dysgranular insular cortex (Fig. 5B). We dissected all input nuclei into eight areas. The majority of input nuclei were located in the isocortex $(35.72 \% \pm 4.34 \%)$, followed by the hippocampal formation $\quad(18.92 \% \pm 2.52 \%), \quad$ thalamus $(15.65 \% \pm 3.05 \%)$, pallidum $(8.25 \% \pm 4.01 \%)$, hypothalamus $(5.93 \% \pm 1.91 \%)$, midbrain $(4.36 \% \pm 1.31 \%)$, olfactory areas $(4.02 \% \pm 2.01 \%)$, and striatum $(2.32 \% \pm 1.13 \%)$ (Fig. 6D).

\section{Comparison of Inputs between Different Cell Types}

To determine the quantitative differences in input distributions among different cells and subzones, we compared the input percentages of each nucleus between $\mathrm{VGLUT2}^{+}$ and $\mathrm{PV}^{+}$neurons in the BLA (Fig. 6A) and between PKC$\delta^{+}$and $\mathrm{SST}^{+}$GABAergic neurons in the CeA (Fig. 6B).
Taking all regions (percentages $>1 \%$ ) into calculation, the VLGUT2 $^{+}$neurons received more projections from the $\mathrm{CPu}$ and $\mathrm{CA} 1$ than the $\mathrm{PV}^{+}$neurons $(P<0.0001$, $P<0.0001$, Fig. 6A), whereas the Pir sent more projections to the $\mathrm{PV}^{+}$neurons than to the VGLUT2 ${ }^{+}$neurons in the BLA $(P<0.0001$, Fig. 6A). We also found that the $\mathrm{SST}^{+}$neurons received more projections from the temporal association cortex and CA1 than the $\mathrm{PKC}-\delta^{+}$neurons ( $P=0.002, P<0.0001$, Fig. 6B). Although the distribution was highly variable, the input percentages of some brain regions, such as the $\mathrm{AI}, \mathrm{Au}$, and $\mathrm{SI}$, showed no significant differences.

We divided the whole brain into eight areas according to the Allen Mouse Common Coordinate Framework and Reference Atlas and calculated the input percentages among the different brain areas (Fig. 6C, D). Most input projections to the amygdala came from the cortex, and significant differences were found among the four cell types. In detail, there were significantly higher input percentages from the olfactory areas to the $\mathrm{BLA} \mathrm{PV}^{+}$ neurons than to the BLA VGLUT2 $^{+}$interneurons $(P=0.0155)$, and the striatum sent significantly more projections to the BLA VGLUT2 ${ }^{+}$interneurons than to the $\mathrm{BLA} \mathrm{PV}^{+}$neurons $\left(P<0.0001\right.$, Fig. 6C). The CeA SST ${ }^{+}$ neurons received more inputs than the $\mathrm{CeA} \mathrm{PKC}-\delta^{+}$ neurons from the isocortex $(P=0.0114)$ and hippocampal formation $(P=0.0250$, Fig. 6D). In addition, the striatum sent more projections to the $\mathrm{CeA} \mathrm{PKC}-\delta^{+}$neurons than to the $\mathrm{SST}^{+}$neurons $(P<0.0001$, Fig. 6D).

We found several novel projections not reported previously. The BLA VGLUT2 ${ }^{+}$and $\mathrm{PV}^{+}$neurons both received projections from the SI $(2.60 \%$ and $4.58 \%$, respectively). The $\mathrm{CeA} \mathrm{PKC}-\delta^{+}$neurons received projections from the SI (1.93\%), deep mesencephalic nucleus $(2.51 \%)$, tuber cinereum area $(3.09 \%)$, and zona incerta (ZI) $(0.80 \%)$. The $\mathrm{CeA} \mathrm{SST}^{+}$neurons received projections from the SI (1.97\%) and deep mesencephalic nucleus $(2.55 \%)$. 
A
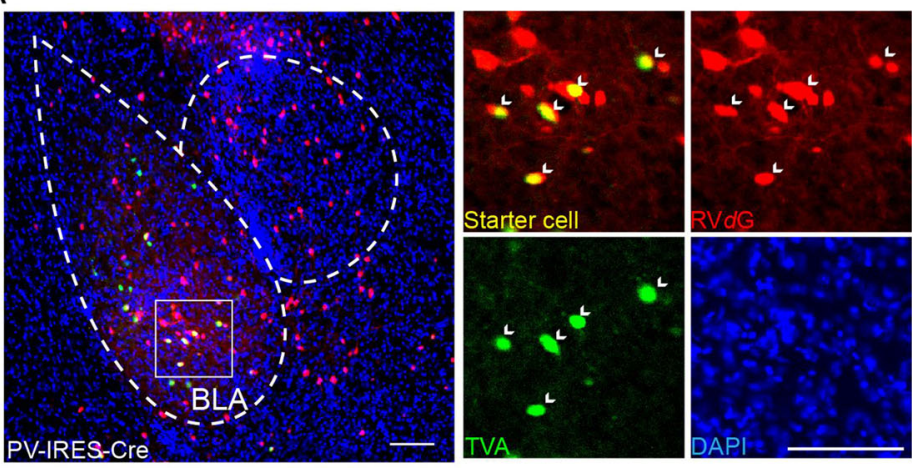

C

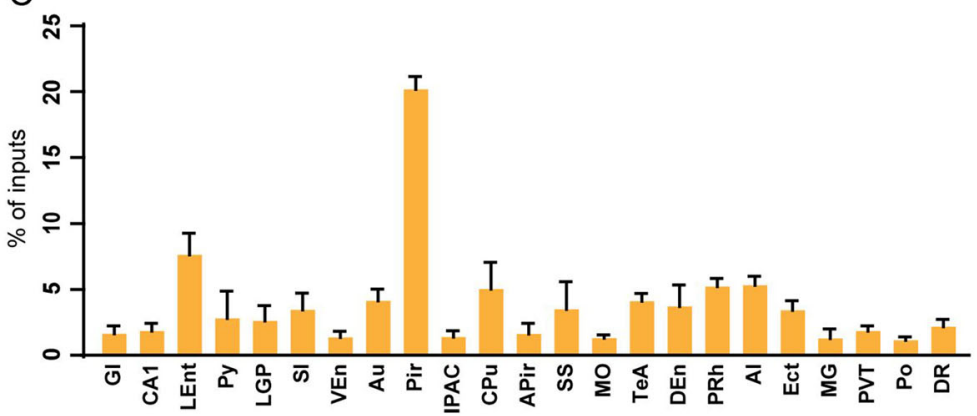

D

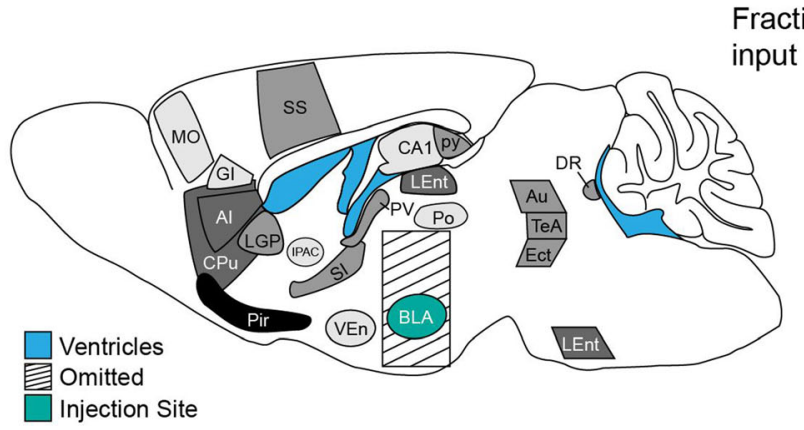

Fig. 3 Long-range inputs to $\mathrm{BLA} \mathrm{PV}^{+}$GABAergic neurons. A Representative images of starter cells restricted to the BLA. Starter cells expressed both GFP and dsRed fluorescent proteins were marked by arrowheads. Scale bars, $100 \mu \mathrm{m}$. B Representative images of RVlabeled input neurons to $\mathrm{BLA} \mathrm{PV}^{+}$neurons from selected nuclei.

\section{Discussion}

We used a modified rabies virus retrograde tracing system to map whole-brain long-range inputs to the BLA and CeA. In total, 37 individual brain regions projected to the BLA VGLUT2 $^{+}$glutamatergic neurons and 78 regions projected to the $\mathrm{BLA} \mathrm{PV}^{+}$GABAergic neurons. In the CeA, $\mathrm{PKC}-\delta^{+}$ GABAergic neurons received projections from 104 regions and $\mathrm{SST}^{+}$GABAergic neurons received innervation from 89 regions. These data together built a detailed map of the long-range projections from the whole brain to specific neuronal types in the amygdala.

\section{B}
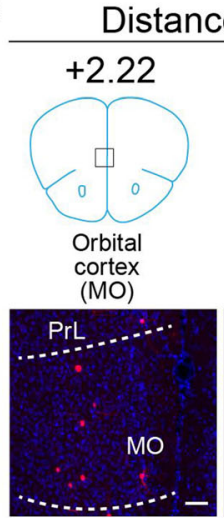

$-0.95$

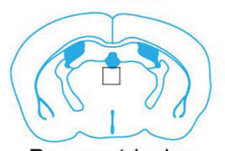

Paraventricular thalamic nuc
(PVT)

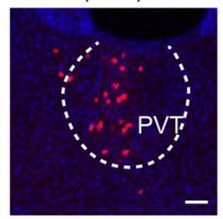

$-2.46$
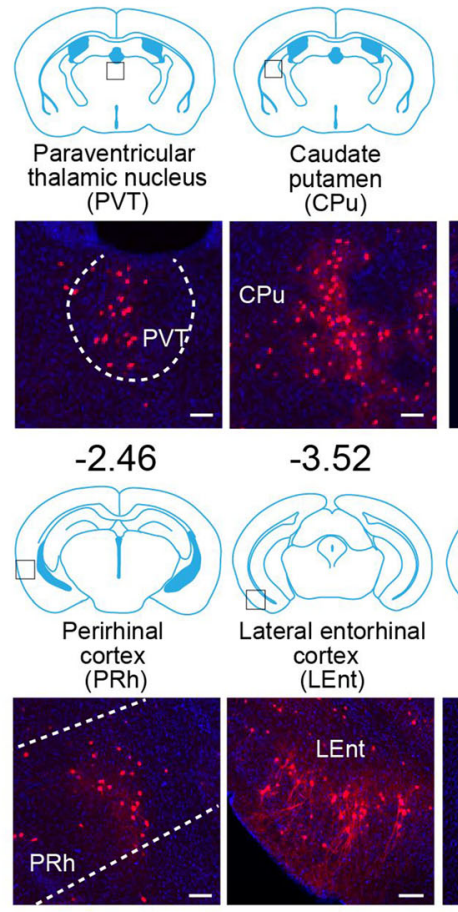

$-3.52$

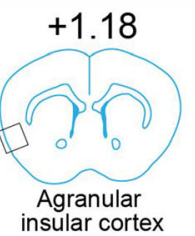

(Al)

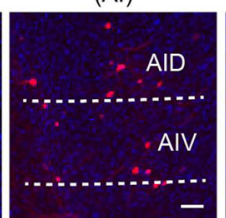

$-0.95$
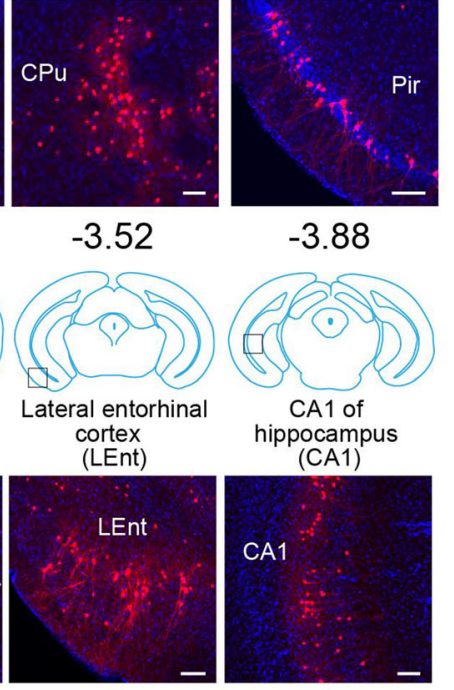

$-3.88$

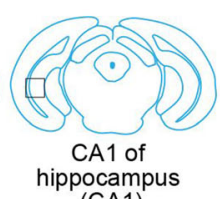

(CA1)

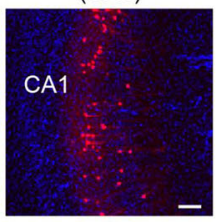

Scale bars, $100 \mu \mathrm{m}$. C Whole-brain distribution of input nuclei to $\mathrm{BLA} \mathrm{PV}^{+}$neurons with input percentages $>1 \%$ (mean \pm SEM). D Schematic summary of regions providing the largest average fractional inputs to $\mathrm{BLA} \mathrm{PV}^{+}$neurons. Abbreviations are shown in Table 1.

Our trans-synaptic tracing data demonstrated that several nuclei exhibited input preferences to different cell types in the amygdala. For example, we found that the BLA VGLUT2 ${ }^{+}$neurons received significantly more projections from CA1 than the $\mathrm{PV}^{+}$neurons. Considering the role that projections from CA1 to the BLA play in fear conditioning and the massive intrinsic connections in the amygdala, this projection preference possibly indicates that glutamatergic neurons are the main input sites for sensory information, and $\mathrm{PV}^{+}$interneurons are the modulators of principal neurons in the BLA [17, 34-36]. In addition, our data showed that the $\mathrm{PV}^{+}$neurons received more 


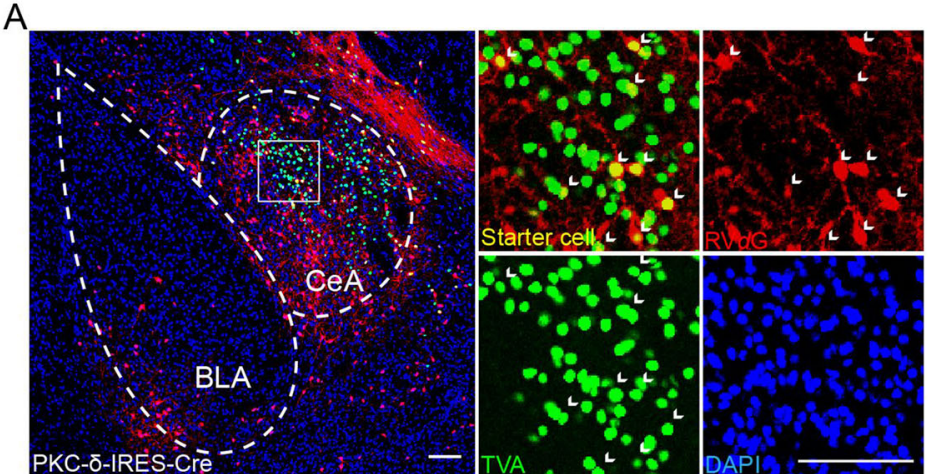

C

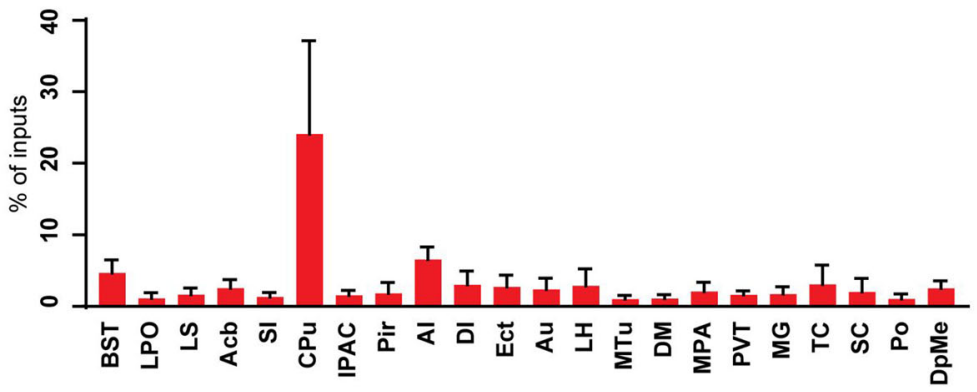

D

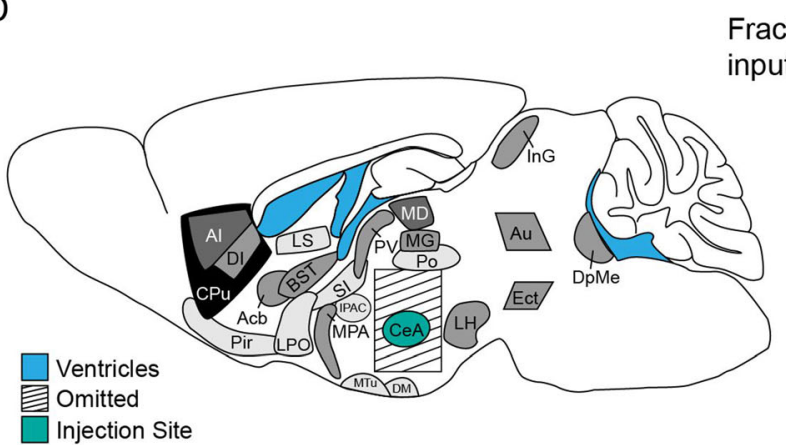

Fig. 4 Long-range inputs to $\mathrm{CeA} \mathrm{PKC}-\delta^{+}$GABAergic neurons. A Representative images of starter cells restricted to the CeA. Starter cells expressed both GFP and dsRed fluorescent proteins were marked by arrowheads. Scale bars, $100 \mu \mathrm{m}$. B Representative images of RV-labeled input neurons to $\mathrm{CeA} \mathrm{PKC}-\delta^{+}$neurons from selected

projections from the Pir than the VGLUT2 ${ }^{+}$neurons. The Pir has a unique bidirectional connection with the BLA, which may be important in the association of different meanings with different odors [37]. Our findings suggest that $\mathrm{PV}^{+}$neurons may be involved in odor information processing [36, 38]. In the CeA, we found that $\mathrm{SST}^{+}$ neurons received more projections from CA1 than $\mathrm{PKC}-\delta^{+}$ neurons. Projections from $\mathrm{CA} 1$ to the $\mathrm{CeA}$ are necessary for the context-dependent retrieval of cued fear memories [35]. Considering the different roles of PKC- $\delta^{+}$and $\mathrm{SST}^{+}$ neurons in conditioned fear [17,39], these data suggest that $\mathrm{CeA} \mathrm{SST}{ }^{+}$neurons are strongly associated with the retrieval of cued fear memories related to the hippocampus.
B

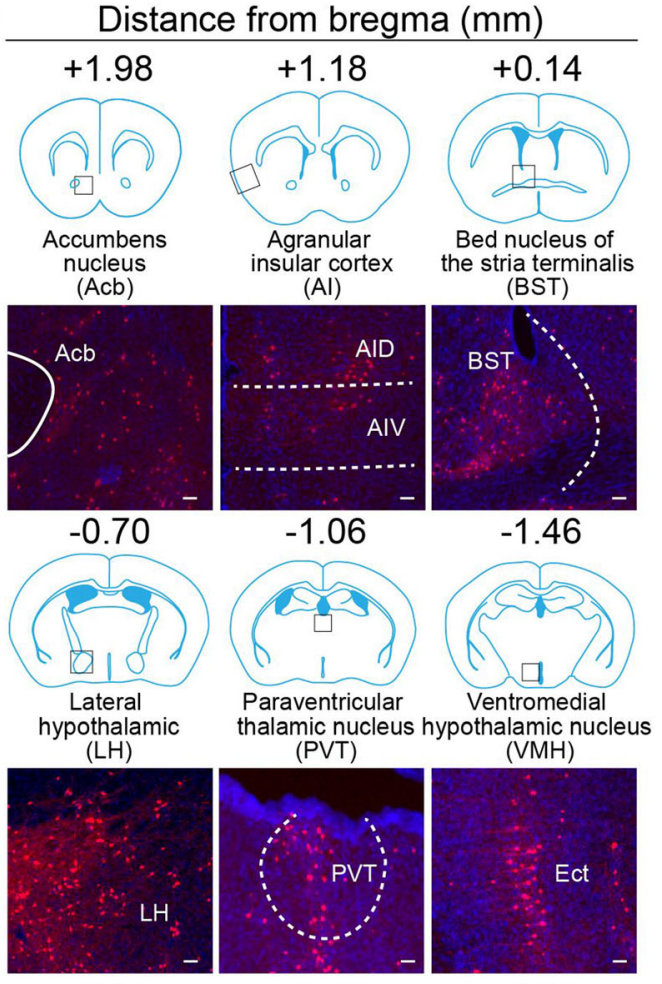

$-1.94$

$-2.46$

$-4.36$
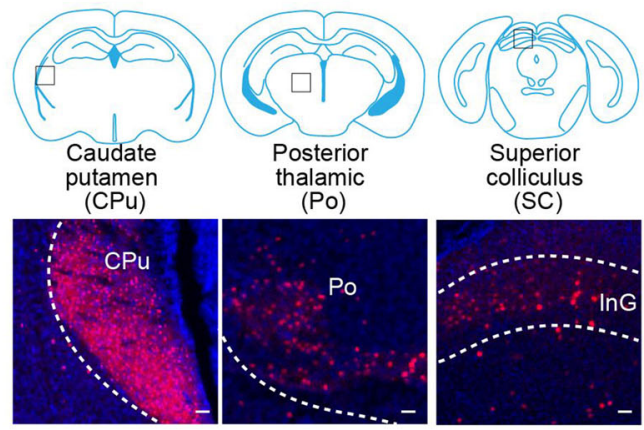

nuclei. Scale bars, $100 \mu \mathrm{m}$. C Whole-brain distribution of input nuclei to $\mathrm{CeA} \mathrm{PKC}-\delta^{+}$neurons with input percentages $>1 \%$ (mean \pm SEM). D Schematic summary of regions providing the largest average fractional inputs to $\mathrm{CeA} \mathrm{PKC}-\delta^{+}$neurons. Abbreviations are shown in Table 1.

Thus, these projection preferences indicate differences in connections and functions between different types of amygdala neurons.

The BLA is widely considered to be the sensory gateway to the amygdala [40]. As expected, our tracing results showed projections from the $\mathrm{mPFC}$ - consisting of the prelimbic and infralimbic cortex - to $\mathrm{BLA} \mathrm{PV}^{+}$ interneurons (Table $\mathrm{S} 1$ ), in accordance with a prior study showing that opto-activation of the mPFC-to-BLA projection increases food intake behavior in mice [41]. The CeA is an important region of the amygdala, orchestrating a diverse set of behaviors, including fear, anxiety, and defensive responses [2, 42, 43]. Our rabies virus input- 


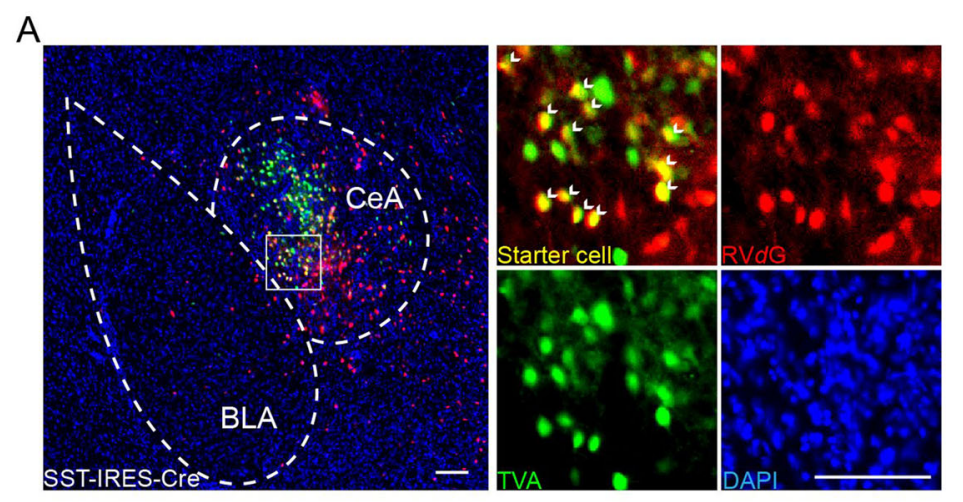

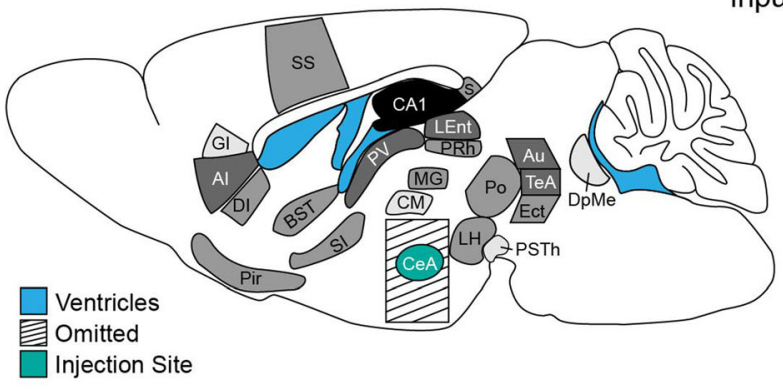

Fig. 5 Long-range inputs to $\mathrm{CeA} \mathrm{SST}^{+}$GABAergic neurons. A Representative images of starter cells restricted to the CeA. Starter cells expressed both GFP and dsRed fluorescent proteins were marked by arrowheads. Scale bars, $100 \mu \mathrm{m}$. B Representative images of $\mathrm{RV}$-labeled input neurons to $\mathrm{CeA} \mathrm{SST}{ }^{+}$neurons from selected

tracing identified several principal input regions reported in previous studies, such as the PVT [44], AI [45], BST [46], and substantia nigra pars compacta [47] (Figs 4 and 5, Table S1). Projections from the lateral parabrachial nucleus to the CeA may be essential for sodium intake [48-50]. We observed that the lateral parabrachial neurons were labeled with RV-dsRed in the $\mathrm{SST}^{+}$neuron retrograde tracing (Table S1), indicating that $\mathrm{SST}^{+}$neurons may be involved in salt appetitive behavior. Our results help to understand the heterogeneity of the amygdala and provide potential directions for further studies.

With the application of the rabies virus retrograde-tracing system, we identified several novel projections to the
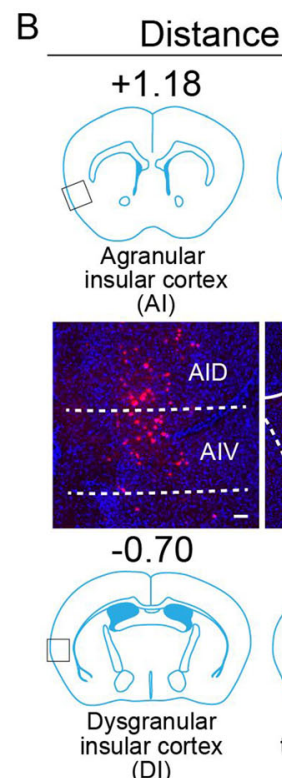

(DI)

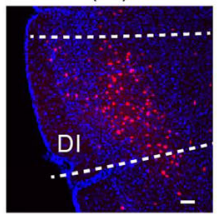

$-2.46$

Fraction of dsRed+ input neurons
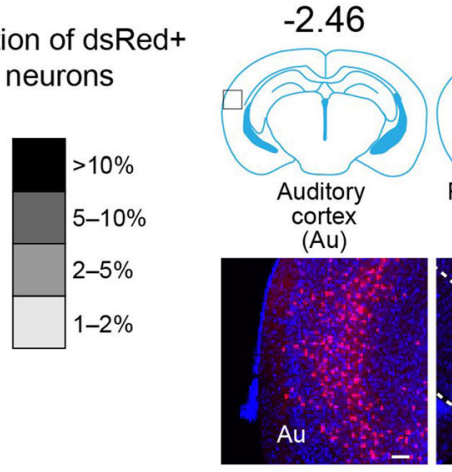

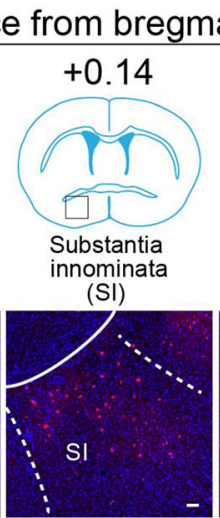

$-1.06$
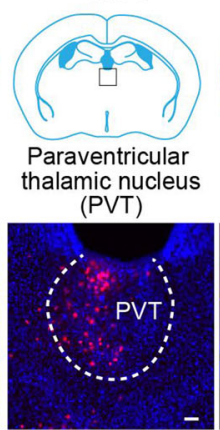

$-2.46$

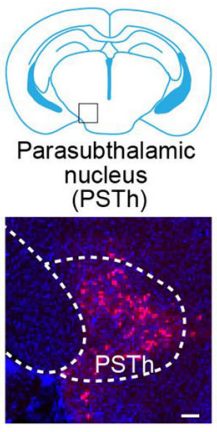

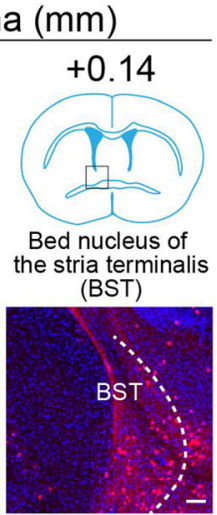

$-2.46$

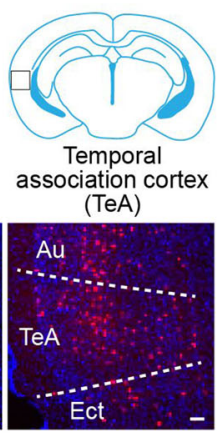

$-3.64$

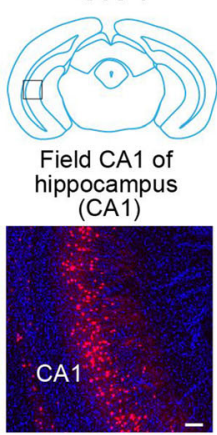

nuclei. Scale bars, $100 \mu \mathrm{m}$. C Whole-brain distribution of input nuclei to $\mathrm{CeA} \mathrm{SST}^{+}$neurons with input percentages $>1 \%$ (mean \pm SEM). D Schematic summary of regions providing the largest average fractional inputs to $\mathrm{CeA} \mathrm{SST}^{+}$neurons. Abbreviations are shown in Table 1.

amygdala that have not been reported previously, including projections from the SI to both $\mathrm{CeA} \mathrm{PKC}-\delta^{+}$and $\mathrm{SST}^{+}$ neurons (Figs 4 and 5). The lateral central amygdala (CeL) PKC- $\delta^{+}$-to-SI neural circuit modulates negative reinforcement learning [51]. Our findings suggest that the SI may have bidirectional connections with the CeA GABAergic neurons, possibly extending the roles of the latter in encoding motivation, fear conditioning, and conditioned reinforcement [51]. Interestingly, our trans-synaptic tracing results demonstrated a ZI-to-CeA PKC- $\delta^{+}$neural circuit (Table S1). Stimulation of the ZI can be used to treat fear generalization [52]. Combined with recent findings on the functions of the ZI (eating, hunting, and sleeping) [53] and 

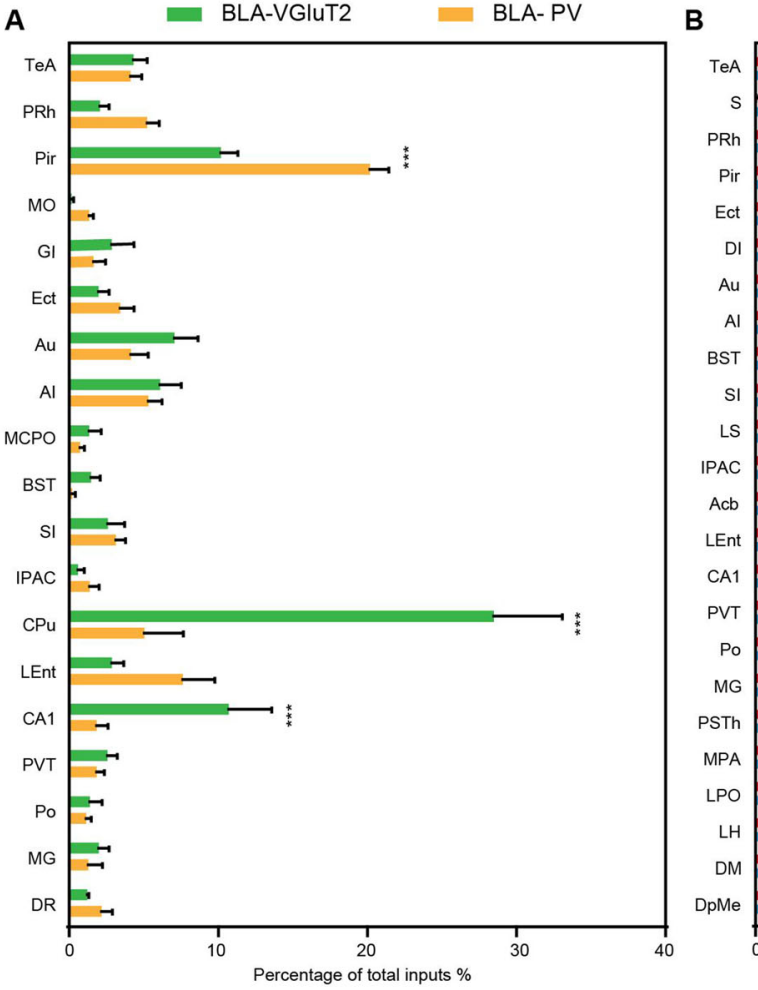

Fig. 6 Comparison of input percentages of different nuclei among different cell types. A Comparison of input percentages from different nuclei in VGLUT2-IRES-Cre and PV-IRES-Cre mice $(n=4$, $* * * P<0.001$, mean $\pm \mathrm{SEM})$. B Comparison of input percentages in PKC- $\delta$-IRES-Cre and SST-IRES-Cre mice $\quad(n=4, \quad * * P<0.01$,

the role of $\mathrm{CeA} \mathrm{PKC}-\delta^{+}$neurons in conditioned fear $[17,30]$, these novel projections may provide another explanation for how the ZI reacts in fear modulation and extend the potential roles of the amygdala in different functions. However, further optogenetic and electrophysiological studies are required to clarify these questions.

Previous study has revealed that direct glutamatergic projections from the cingulate cortex to the BLA participate in innate fear [54]. Our study showed that the BLA VGLUT2 $^{+}$neurons did not receive inputs from the cingulate, whereas the $\mathrm{PV}^{+}$neurons did. This discrepancy could be attributed to the different subtypes studied in the BLA. We did not cover other glutamatergic neuronal subtypes, such as VGLUT1 ${ }^{+}$glutamatergic neurons. The $\mathrm{PV}^{+}$interneurons in the BLA can be divided into four subtypes based on their firing properties, and exhibit subtype-specific heterogeneity in their patterns of local synaptic connections, as well as in CeL early-spiking and late-spiking neurons [55]. It is difficult to distinguish the heterogeneities of these $\mathrm{PV}^{+}$CeL early-spiking and latespiking neurons in long-range connections with rabies virus tracing due to a lack of specific molecular markers for these subtypes. Thus, further studies combined with optogenetics
$* * * P<0.001)$. C Percentage of total inputs from selected regions for BLA glutamatergic and $\mathrm{PV}^{+}$neurons $(n=4, * P<0.05$, $* * * * P<0.0001)$. D Percentage of total inputs from selected regions for $\mathrm{CeA} \quad \mathrm{PKC}-\delta^{+}$and $\mathrm{SST}^{+}$neurons $(n=4, \quad * P<0.05$, $* * * * P<0.0001)$. Abbreviations are shown in Table 1.

and electrophysiological analysis are required to solve this issue. Using immunohistochemical and cholera toxin B tracing methods, previous studies have shown that the central and basal amygdala are targets of dopaminergic terminals [56-60]. We observed inputs from the mesencephalic dopaminergic system, such as from the substantia nigra and ventral tegmental area (VTA) to the $\mathrm{BLA} \mathrm{PV}^{+}$ neurons $(<1 \%$, see Table $\mathrm{S} 1)$ and from the substantia nigra pars compacta, VTA, periaqueductal gray, and dorsal raphe to the $\mathrm{CeA} \mathrm{PKC}-\delta^{+}$and $\mathrm{SST}^{+}$neurons $(<1 \%$, see Table S1), supporting the idea that these dopaminergic areas may form synapses in the amygdala. However, these sparse inputs could be the result of the limitations of the monosynaptic rabies virus-tracing system used in neuromodulatory projections such as dopaminergic transmission. It is likely that the extracellular space between the dopaminergic terminals and neurons in the amygdala does not allow the rabies virus particles to traverse effectively [61]. Further studies are required to test this possibility.

There are some limitations in this study. First, it was difficult to obtain the complete olfactory bulb when removing the brain, so we did not count input cells in the olfactory bulb. Second, the amygdala has very strong 
intranuclear and internuclear connectivity, such as separate projections from the BLA to CeA PKC- $\delta^{+}$and $\mathrm{SST}^{+}$ neurons [17]. However, due to the leakage of rabies virus at the injection site, the intra-amygdala connections were excluded from our data, and regions around the BLA and $\mathrm{CeA}$ were omitted from analysis (e.g., the medial and basomedial amygdalar nuclei) [62]. Third, due to the limitation of transgenic mouse strains, we could not cover all neuronal subtypes in the amygdala, e.g., calbindin and calretinin GABAergic neurons in the BLA [22] and corticotropin-releasing factor and neurotensin-expressing neurons in the CeA [25]. As such, additional research on these important neuronal subtypes is required to address this issue.

Taking the above data into consideration, most afferent inputs to the amygdala came from the cortex, striatum, hippocampus, and thalamus, with great variation among the different cell types. Our research supports the idea of the amygdala as a node that contributes to multiple behaviors, as it received a varied and wide range of input projections from the whole brain. Furthermore, our study revealed a wide range of inputs to different molecular marker-labeled neurons in the amygdala. These findings will help to fully understand the roles of glutamatergic neurons and different GABAergic subtypes in the amygdala in different behaviors.

Acknowledgements This work was supported by the Key Project of the National Natural Science Foundation of China (31430034), the National Key Research and Development Project of the Ministry of Science and Technology of China (2016YF051000), the Science and Technology Program of Guangdong Province, China (2018B030334001), the Key Realm R\&D Program of Guangdong Province, China (2019B030335001), Funds for Creative Research Groups of China from the National Natural Science Foundation of China (81521062), and the Non-Profit Central Research Institute Fund of the Chinese Academy of Medical Sciences (2019PT310023). We thank H.H. Li (Huazhong University of Science and Technology, Wuhan, China) and L. Wang (Zhejiang University, Hangzhou, China) for kindly providing the mouse line. We thank the Core Facilities of the Zhejiang University Institute of Neuroscience for technical support.

Conflicts of interest The authors declare no conflicts of interest.

Open Access This article is licensed under a Creative Commons Attribution 4.0 International License, which permits use, sharing, adaptation, distribution and reproduction in any medium or format, as long as you give appropriate credit to the original author(s) and the source, provide a link to the Creative Commons licence, and indicate if changes were made. The images or other third party material in this article are included in the article's Creative Commons licence, unless indicated otherwise in a credit line to the material. If material is not included in the article's Creative Commons licence and your intended use is not permitted by statutory regulation or exceeds the permitted use, you will need to obtain permission directly from the copyright holder. To view a copy of this licence, visit http://creativecommons. org/licenses/by/4.0/.

\section{References}

1. Schiff HC, Bouhuis AL, Yu K, Penzo MA, Li H, He M, et al. An insula-central amygdala circuit for guiding tastant-reinforced choice behavior. J Neurosci 2018, 38: 1418-1429.

2. Yu K, Garcia da Silva P, Albeanu DF, Li B. Central amygdala somatostatin neurons gate passive and active defensive behaviors. J Neurosci 2016, 36: 6488-6496.

3. Yu K, Ahrens S, Zhang X, Schiff H, Ramakrishnan C, Fenno L, et al. The central amygdala controls learning in the lateral amygdala. Nat Neurosci 2017, 20: 1680-1685.

4. Baxter MG, Murray EA. The amygdala and reward. Nat Rev Neurosci 2002, 3: 563-573.

5. Douglass AM, Kucukdereli H, Ponserre M, Markovic M, Grundemann J, Strobel C, et al. Central amygdala circuits modulate food consumption through a positive-valence mechanism. Nat Neurosci 2017, 20: 1384-1394.

6. Wang SS, Yan XB, Hofman MA, Swaab DF, Zhou JN. Increased expression level of corticotropin-releasing hormone in the amygdala and in the hypothalamus in rats exposed to chronic unpredictable mild stress. Neurosci Bull 2010, 26: 297-303.

7. He F, Ai H, Wang M, Wang X, Geng X. Altered neuronal activity in the central nucleus of the amygdala induced by restraint waterimmersion stress in rats. Neurosci Bull 2018, 34: 1067-1076.

8. LeDoux JE, Farb C, Ruggiero DA. Topographic organization of neurons in the acoustic thalamus that project to the amygdala. J Neurosci 1990, 10: 1043-1054.

9. LeDoux JE, Cicchetti P, Xagoraris A, Romanski LM. The lateral amygdaloid nucleus: sensory interface of the amygdala in fear conditioning. J Neurosci 1990, 10: 1062-1069.

10. McDonald AJ. Cortical pathways to the mammalian amygdala. Prog Neurobiol 1998, 55: 257-332.

11. Turner BH, Herkenham M. Thalamoamygdaloid projections in the rat: a test of the amygdala's role in sensory processing. J Comp Neurol 1991, 313: 295-325.

12. Linke R, Braune G, Schwegler H. Differential projection of the posterior paralaminar thalamic nuclei to the amygdaloid complex in the rat. Exp Brain Res 2000, 134: 520-532.

13. Shen CJ, Zheng D, Li KX, Yang JM, Pan HQ, Yu XD, et al. Cannabinoid CB1 receptors in the amygdalar cholecystokinin glutamatergic afferents to nucleus accumbens modulate depressive-like behavior. Nat Med 2019, 25: 337-349.

14. Fadok JP, Markovic M, Tovote P, Luthi A. New perspectives on central amygdala function. Curr Opin Neurobiol 2018, 49: 141-147.

15. LeDoux JE. Emotion circuits in the brain. Annu Rev Neurosci 2000, 23: 155-184.

16. Dong P, Wang H, Shen XF, Jiang P, Zhu XT, Li Y, et al. A novel cortico-intrathalamic circuit for flight behavior. Nat Neurosci 2019, 22: 941-949.

17. Duvarci S, Pare D. Amygdala microcircuits controlling learned fear. Neuron 2014, 82: 966-980.

18. Poulin JF, Castonguay-Lebel Z, Laforest S, Drolet G. Enkephalin co-expression with classic neurotransmitters in the amygdaloid complex of the rat. J Comp Neurol 2008, 506: 943-959.

19. Vereczki VK, Veres JM, Muller K, Nagy GA, Racz B, Barsy B, et al. Synaptic organization of perisomatic GABAergic inputs onto the principal cells of the Mouse basolateral amygdala. Front Neuroanat 2016, 10: 20.

20. Bienvenu TC, Busti D, Magill PJ, Ferraguti F, Capogna M. Celltype-specific recruitment of amygdala interneurons to hippocampal theta rhythm and noxious stimuli in vivo. Neuron 2012, 74: 1059-1074.

21. Spampanato J, Polepalli J, Sah P. Interneurons in the basolateral amygdala. Neuropharmacology 2011, 60: 765-773. 
22. McDonald AJ, Mascagni F. Colocalization of calcium-binding proteins and GABA in neurons of the rat basolateral amygdala. Neuroscience 2001, 105: 681-693.

23. Kim J, Zhang X, Muralidhar S, LeBlanc SA, Tonegawa S. Basolateral to central amygdala neural circuits for appetitive behaviors. Neuron 2017, 93: 1464-1479 e1465.

24. Ehrlich I, Humeau Y, Grenier F, Ciocchi S, Herry C, Luthi A. Amygdala inhibitory circuits and the control of fear memory. Neuron 2009, 62: 757-771.

25. McCullough KM, Morrison FG, Hartmann J, Carlezon WA, Jr., Ressler KJ. Quantified coexpression analysis of central amygdala subpopulations. eNeuro 2018, 5.

26. Vong L, Ye C, Yang Z, Choi B, Chua S, Jr., Lowell BB. Leptin action on GABAergic neurons prevents obesity and reduces inhibitory tone to POMC neurons. Neuron 2011, 71: 142-154.

27. Hippenmeyer S, Vrieseling E, Sigrist M, Portmann T, Laengle C, Ladle DR, et al. A developmental switch in the response of DRG neurons to ETS transcription factor signaling. PLoS Biol 2005, 3: e159.

28. Taniguchi H, He M, Wu P, Kim S, Paik R, Sugino K, et al. A resource of Cre driver lines for genetic targeting of GABAergic neurons in cerebral cortex. Neuron 2011, 71: 995-1013.

29. Madisen L, Zwingman TA, Sunkin SM, Oh SW, Zariwala HA, $\mathrm{Gu} \mathrm{H}$, et al. A robust and high-throughput Cre reporting and characterization system for the whole mouse brain. Nat Neurosci 2010, 13: 133-140.

30. Haubensak W, Kunwar PS, Cai H, Ciocchi S, Wall NR, Ponnusamy $\mathrm{R}$, et al. Genetic dissection of an amygdala microcircuit that gates conditioned fear. Nature 2010, 468: 270-276.

31. Lein ES, Hawrylycz MJ, Ao N, Ayres M, Bensinger A, Bernard $\mathrm{A}$, et al. Genome-wide atlas of gene expression in the adult mouse brain. Nature 2007, 445: 168-176.

32. Allen Institute for Brain Science. Allen Mouse Common Coordinate Framework. 2017. http://help.brain-map.org/down load/attachments/8323525/Mouse_Common_Coordinate_Frame work.pdf?version $=3$.

33. Callaway EM, Luo L. Monosynaptic circuit tracing with glycoprotein-deleted rabies viruses. J Neurosci 2015, 35: 8979-8985.

34. Kim WB, Cho JH. Synaptic targeting of double-projecting ventral CA1 hippocampal neurons to the medial prefrontal cortex and basal amygdala. J Neurosci 2017, 37: 4868-4882.

35. Xu C, Krabbe S, Grundemann J, Botta P, Fadok JP, Osakada F, et al. Distinct hippocampal pathways mediate dissociable roles of context in memory retrieval. Cell 2016, 167: 961-972 e916.

36. Krabbe S, Grundemann J, Luthi A. Amygdala inhibitory circuits regulate associative fear conditioning. Biol Psychiatry 2018, 83: 800-809.

37. Illig KR, Wilson DA. Olfactory cortex: comparative anatomy. In: Reference Module in Biomedical Sciences, 2014

38. Johnson DM, Illig KR, Behan M, Haberly LB. New features of connectivity in piriform cortex visualized by intracellular injection of pyramidal cells suggest that "primary" olfactory cortex functions like "association" cortex in other sensory systems. J Neurosci 2000, 20: 6974-6982.

39. Ciocchi S, Herry C, Grenier F, Wolff SB, Letzkus JJ, Vlachos I, et al. Encoding of conditioned fear in central amygdala inhibitory circuits. Nature 2010, 468: 277-282.

40. LeDoux J. The amygdala. Curr Biol 2007, 17: R868-874.

41. Land BB, Narayanan NS, Liu RJ, Gianessi CA, Brayton CE, Grimaldi DM, et al. Medial prefrontal D1 dopamine neurons control food intake. Nat Neurosci 2014, 17: 248-253.

42. Penzo MA, Robert V, Li B. Fear conditioning potentiates synaptic transmission onto long-range projection neurons in the lateral subdivision of central amygdala. J Neurosci 2014, 34: 2432-2437.

43. Janak PH, Tye KM. From circuits to behaviour in the amygdala. Nature 2015, 517: 284-292.
44. Penzo MA, Robert V, Tucciarone J, De Bundel D, Wang M, Van Aelst L, et al. The paraventricular thalamus controls a central amygdala fear circuit. Nature 2015, 519: 455-459.

45. Venniro M, Caprioli D, Zhang M, Whitaker LR, Zhang S, Warren $\mathrm{BL}$, et al. The anterior insular cortex->central amygdala glutamatergic pathway is critical to relapse after contingency management. Neuron 2017, 96: 414-427 e418.

46. Yamauchi N, Takahashi D, Sugimura YK, Kato F, Amano T, Minami M. Activation of the neural pathway from the dorsolateral bed nucleus of the stria terminalis to the central amygdala induces anxiety-like behaviors. Eur J Neurosci 2018, 48: 3052-3061.

47. Lee HJ, Youn JM, Gallagher M, Holland PC. Temporally limited role of substantia nigra-central amygdala connections in surpriseinduced enhancement of learning. Eur J Neurosci 2008, 27: 3043-3049.

48. Andrade-Franze GM, Andrade CA, De Luca LA, Jr., De Paula PM, Menani JV. Lateral parabrachial nucleus and central amygdala in the control of sodium intake. Neuroscience 2010, 165: 633-641.

49. Andrade-Franze GM, Gasparini S, De Luca LA, Jr., De Paula PM, Colombari DS, Colombari E, et al. Lateral parabrachial nucleus and opioid mechanisms of the central nucleus of the amygdala in the control of sodium intake. Behav Brain Res 2017, 316: 11-17.

50. Andrade-Franze GM, Andrade CA, De Luca LA, Jr., De Paula PM, Colombari DS, Menani JV. Lesions in the central amygdala impair sodium intake induced by the blockade of the lateral parabrachial nucleus. Brain Res 2010, 1332: 57-64.

51. Cui Y, Lv G, Jin S, Peng J, Yuan J, He X, et al. A central amygdala-substantia innominata neural circuitry encodes aversive reinforcement signals. Cell Rep 2017, 21: 1770-1782.

52. Venkataraman A, Brody N, Reddi P, Guo J, Gordon Rainnie D, Dias BG. Modulation of fear generalization by the zona incerta. Proc Natl Acad Sci U S A 2019, 116: 9072-9077.

53. Wang X, Chou XL, Zhang LI, Tao HW. Zona incerta: An integrative node for global behavioral modulation. Trends Neurosci 2020, 43: 82-87.

54. Jhang J, Lee H, Kang MS, Lee HS, Park H, Han JH. Anterior cingulate cortex and its input to the basolateral amygdala control innate fear response. Nat Commun 2018, 9: 2744.

55. Hou WH, Kuo N, Fang GW, Huang HS, Wu KP, Zimmer A, et al. Wiring specificity and synaptic diversity in the mouse lateral central amygdala. J Neurosci 2016, 36: 4549-4563.

56. Chu HY, Ito W, Li J, Morozov A. Target-specific suppression of GABA release from parvalbumin interneurons in the basolateral amygdala by dopamine. J Neurosci 2012, 32: 14815-14820.

57. Pinard CR, Muller JF, Mascagni F, McDonald AJ. Dopaminergic innervation of interneurons in the rat basolateral amygdala. Neuroscience 2008, 157: 850-863.

58. Groessl F, Munsch T, Meis S, Griessner J, Kaczanowska J, Pliota $\mathrm{P}$, et al. Dorsal tegmental dopamine neurons gate associative learning of fear. Nat Neurosci 2018, 21: 952-962.

59. Asan E. Ultrastructural features of tyrosine-hydroxylase-immunoreactive afferents and their targets in the rat amygdala. Cell Tissue Res 1997, 288: 449-469.

60. de la Mora MP, Gallegos-Cari A, Arizmendi-Garcia Y, Marcellino D, Fuxe K. Role of dopamine receptor mechanisms in the amygdaloid modulation of fear and anxiety: Structural and functional analysis. Prog Neurobiol 2010, 90: 198-216.

61. Wall NR, De La Parra M, Callaway EM, Kreitzer AC. Differential innervation of direct- and indirect-pathway striatal projection neurons. Neuron 2013, 79: 347-360.

62. Schwarz LA, Miyamichi K, Gao XJ, Beier KT, Weissbourd B, DeLoach KE, et al. Viral-genetic tracing of the input-output organization of a central noradrenaline circuit. Nature 2015, 524: 88-92. 